\title{
ACONTECIMENTO, ARQUIVO, MEMÓRIA: ÀS MARGENS DA LEI ${ }^{*}$
}

\section{Mónica G. Zoppi-Fontana ${ }^{(*)}$}

Resumo: O artigo desenvolve uma análise da legislação do Município de Campinas (SP) sobre uso e ocupação do espaço público urbano a partir de um corpus de natureza longitudinal que cobre o período de 1974 a 2001. A partir das análises, realiza-se uma reflexão sobre os conceitos de acontecimento, arquivo e memória no campo teórico da Análise de Discurso Francesa. Apresentam-se, também, considerações sobre as práticas de escritura de lei na sua relação com o funcionamento do arquivo jurídico.

Palavras-chave: leitura e escrita, discurso jurídico, saber urbano e linguagem, ideologia, interpretação

\section{Introdução}

Do direito romano até o código civil, que constitui a sua racionalização burguesa, o direito continental europeu se apóia sobre o sistema regulamentar de um texto redigido, que tende a constituir a unidade abstrata de uma Razão escrita, feita para ser aplicada à totalidade das conjunturas da prática jurídica. Na sua origem, o direito continental é um direito erudito, letrado, doutrinal, exercido por especialistas dotados de uma formação universitária em que o latim traz sua "lógica" ao pensamento jurídico. Nessa ordem universal da doutrina, a nomenclatura das categorias do direito romano constitui por seu sistema de sanções ao mesmo tempo um modelo de organização social ẹ um dispositivo moral de formação dos comportamentos.

Neste trabalho propomos uma reflexão sobre o funcionamento da memória e do acontecimento discursivos na produção de sentido,

" Uma primeira versão abreviada deste texto foi apresentada no I Congresso Internacional da Abralin, realizado na UFSC, Florianópolis, em fevereiro de 1999. Na sua versão atual, o texto retoma e amplia algumas análises desenvolvidas em Zoppi-Fontana, M. (1999a).

(*) Doutora em Lingüística pela Unicamp. Professora do Departamento de Lingüística do Instituto de Estudos da Linguagem/Unicamp.

I GADET, F. \& PECHEUX, M., 1981, p. 189-190. 
especificamente em arquivos institucionalizados. Com esse objetivo, investigamos os processos de significação que interpretam o espaço público urbano a partir do discurso da lei em relação com a ocupação e uso do solo da cidade pelos camelôs.

As análises focalizam o funcionamento da legislação municipal da cidade de Campinas (SP). Para isso, realizamos um levantamento longitudinal dos textos legais desde 1974, ano da criação da autarquia municipal que regula e fiscaliza a utilização do solo público (SETEC) até 2001, (ano do decreto municipal que estabelece taxas devidas pela utilização do solo público). Nessa série do arquivo $^{2}$ legal pode observar-se, por um lado, a repetição formal e reformulação parafrástica dos textos legais através do tempo, configurando, assim, uma memória que estabiliza e homogeneiza as resoluções da Prefeitura. Por outro lado, percebe-se, porém, uma ruptura/deslocamento ocorrido nessa série em 1993 (através da Resolução 05/93 da SETEC), que se instala no arquivo como acontecimento discursivo, desorganizando a memória e interrompendo a série de repetições formais e reformulações parafrásticas. Com as análises, almejamos demonstrar que essas rupturas são efeito da irrupção da ordem do político na ordem jurídica do texto legal. Com efeito, nessas resoluções aparecem pela primeira vez no texto legal designações como "camelôs" (as aspas são do texto da lei) e trabalhadores da economia informal que apontam para um exterior ao arquivo legal, que os incorpora como efeitos de pré-construído, i.e., sem definição legal. Assim, verifica-se a irrupção no texto legal de elementos produzidos historicamente em outros espaços de memória, que ao afetá-lo, alteram seu funcionamento, fazendo acontecimento.

Acontecimento e memória discursiva

A questão dos camelôs se configura como um campo discursivo ${ }^{3}$ instável e conflitivo, onde diversas formações discursivas

2 O itálicos sinalizam conceitos que serão discutidos, teoricamente, no decorrer do trabalho.

3 Retomamos as categorias metodológicas propostas por Maingueneau (1987) em relação ao trabalho de constituicão do corpus: universo discursivo - no nosso caso, os discursos sobre a cidade e o espaço urbano -, campo discursivo -os discursos sobre a ocupação e uso do solo público - e espaço discursivo - os discursos sobre a questão dos camelôs. 
colidem em um movimento contínuo de enfrentamento e tentativas de reacomodação, produzindo rupturas na memória discursiva que se materializam como acontecimento discursivo, o qual evidencia o embate ideológico entre as diferentes posições de sujeito a partir das quais se produzem as diversas representações que interpretam o espaço urbano.

Em Langages, 114 (junho 1994), número monográfico organizado por Jean Jacques Courtine, os artigos publicados elaboram teórica e analiticamente a relação entre Memória, história, linguagem. O organizador esclarece na introdução que "A memória que nos interessa é a memória social, coletiva, na sua relação com a linguagem e a história"4. Em seguida, ele conclui: "a linguagem é o tecido da memória, isto é sua modalidade de existência histórica essencial" (grifos do autor; tradução nossa) ${ }^{5}$. Considerando, então, que a linguagem é a materialidade própria da memória histórica de uma sociedade, assumimos que os processos discursivos constituem o espaço simbólico onde é possível observar seu funcionamento. Seguindo a Henry, consideramos que a relação do sujeito com os fatos históricos é uma relação de significação: "não há "fato" ou "evento" histórico que não faça sentido, que não peça interpretação, que não reclame que lhe achemos causas e consequiências. É nisso que consiste para nós a História, nesse fazer sentido, mesmo que possamos divergir sobre esse sentido em cada caso"6. Esses sentidos se sedimentam historicamente como memória discursiva, estratificados e desnivelados pelas relações de força que determinam ideologicamente o discurso". Conforme Orlandi, "a ideologia se liga inextrincavelmente à interpretação enquanto fato fundamental que atesta a relação da história com a língua, na medida em que esta

COURTINE, 1994, p.5.

Ibid., p. 10.

HENRY, 1994, p.52.

Pêcheux (1983) afirma que sustentar que "em certas circunstâncias há independência do objeto face a qualquer discurso feito a seu respeito, significa colocar que, no interior do que se apresenta como o universo físico-humano, há real, isto é, pontos de impossível, determinando açuilo que não pode não ser assim". Em outras palavras, retomando também Pêcheux (1975), o mundo material existe, produzindo efeitos sobre o sujeito. 
significa"8. Assim, entendemos a memória discursiva como espaço ideológico estruturante/estruturado em que se realiza a interpretação, enquanto efeito necessário da relação simbólica estabelecida entre o sujeito e o real da língua e da história. ${ }^{9}$. Efeitos dessa memória se manifestam na linearidade do discurso através de diversos funcionamentos das formas lingüísticas, que se constituem em índices das filiações históricas a partir das quais o sujeito produz interpretação.

Utilizamos, então, o conceito de memória discursiva para designar as redes de filiação histórica que organizam o dizível, dando lugar aos processos de identificação a partir do quais o sujeito encontra as evidências que sustentam/permitem seu dizer (cf. Pêcheux, 1975; Courtine, 1982; Orlandi, 1996). Nesse sentido, a memória discursiva é o espaço dos efeitos de sentido que constituem para o sujeito sua realidade, enquanto representação imaginária (e necessária) da sua relação com o real histórico, no qual ele está inserido.

Sendo fruto da relação da língua com a história, a memória discursiva é constitutivamente afetada pelas falhas que atravessam a língua e as contradições que estruturam a história, o que se materializa no seu caráter necessariamente lacunar e equívoco. "Memória saturada e lacunar, memória com eclipses, onde ressoa somente uma voz sem nome", como diz Courtine (1982). Memória, portanto, estruturada pelo esquecimento, que funciona por uma modalidade de repetição vertical, que é ao mesmo tempo ausente e presente na série de formulações: ausente porque ela funciona sob o modo do desconhecimento, de um não-sabido, não-reconhecido, que se desloca, e presente em seu efeito de retorno, de já-dito, de efeito de préconstruído, de recorrência das formulações, produzindo a estabilidade dos objetos do discurso.

O tecido da memória discursiva se apresenta, assim, como uma trama complexa de fios emaranhados, entrelaçando cores e

ORLANDI, 1999, p.96.

ORLANDI, 1996, p.64, afirma que "A interpretação é uma injunção. Face a qualquer objeto simbólico, o sujeito se encontra na necessidade de "dar" sentido." A autora avança ainda nessa direção identificando o sujeito do discurso à interpretação: "A interpretação faz sujeito" (ibid., p.83). 
texturas distintas em uma superfície que alterna densidade e leveza, opacidade e aparente transparência, excesso e falta de determinação, silêncios, ausências e presenças enfáticas. Superfície espessa que envolve o sujeito nas refrações rarefeitas do ideológico feito sentido no prisma do discurso. ${ }^{10}$

A Teoria da Análise do Discurso propõe o conceito de interdiscurso para trabalhar com a ordem dos processos de constituição dos efeitos de sentido e da própria linearidade do discurso. O interdiscurso é definido como o complexo significante com dominante onde se delimitam as diversas formações discursivas (doravante FD) (Pêcheux, 1975; Courtine, 1982) que se confrontam em uma formação social em uma conjuntura dada. Parte integrante do interdiscurso no qual se delimitam, as FD representam regiões de estabilização da memória discursiva que se organiza por processos de reformulação parafrástica em movimento contínuo de reconfiguração. $O$ interdiscurso afeta a materialidade lingüística das seqüências discursivas, as quais se apresentam, assim, como vestígios do movimento histórico sem fim das FD nas relações de dominação, subordinação, antagonismo e aliança que definem sua configuração.

Assim, compreender o funcionamento dos textos em análise leva a se perguntar o que é enunciar, manter o fio de um discurso, mas também repetir, lembrar, esquecer, para um sujeito enunciador tomado nas contradições históricas (COURTINE, 1982). Achard (1984) permite avançar neste sentido quando chama a atenção para o fato de que a memória suposta pelo discurso é sempre reconstruída na enunciação. Conforme o autor:

A enunciação, então, dever ser tomada, não como advinda do locutor, mas como operações que regulam o encargo, quer dizer a retomada e a circulação do discurso. Entre outras consequiências desta concepção, levaremos em conta o fato de que um texto dado trabalha através de sua circulação social, o que supõe que sua estruturação é uma questão social, e que ela se diferencia seguindo uma diferenciação das memórias e uma

10 Orlandi (2003) trabalha conceitualmente a figura do prisma como modelo explicativo do funcionamento da ideologia e da linguagem no discurso. 
diferenciação das produções de sentido a partir de uma forma única. ${ }^{11}$

Neste trabalho, se nos colocarmos a pergunta do que significa repetir, lembrar, esquecer em relação à tematização do espaço público e da presença dos camelôs nele, e se considerarmos, ainda, a circulação social do discurso ${ }^{12}$ e, por conseguinte, a gestão social da memória, somos levados a pensar o efeito das contradições históricas e ideológicas no funcionamento do arquivo, especificamente, no nosso caso, do arquivo jurídico. Se faz mister, então, observar o cruzamento da ordem do jurídico e da ordem do político nos textos da lei, compreendidos como dispositivos de normalização/normatização da ordem do social $^{13}$.

Para isso, tematizamos o funcionamento de diversos processos discursivos que trabalham no arquivo na construção de sentidos hegemônicos para o espaço público urbano, e analisamos, especialmente, a irrupção no arquivo de sentidos outros que quebram as reformulações parafrásticas estabilizadas como memória, constituindo um acontecimento discursivo que abre espaço para novos processos de significação da cidade.

Para compreender a ruptura dos processos de reformulação parafrástica produzida pelo acontecimento discursivo, vamos considerar o funcionamento da memória discursiva como "espaço de estruturação, de regularização de materialidade discursiva complexa"14. Trabalhando a memória discursiva em relação à prática de leitura, Pêcheux afirma que ela funciona como "aquilo que, face a um texto que surge como acontecimento a ler, vem restabelecer os "implícitos" (em termos técnicos, os pré-construídos, os elementos citados e referidos, os discursos-transversos) de que a leitura necessita"15. Parafraseando o autor, podemos dizer que face a um fato (i.e. ao real histórico), a memória discursiva restabelece um não-dito que permite ao sujeito a interpretação. Assim, a descrição de um

\footnotetext{
11 ACHARD, 1984, p. 17.

12 Cf. ANGENOT, 1984; ORLANDI, 2001; ZOPPI-FONTANA, 2002.

13 Utilizamos o conceito de "ordem de discurso", tal como definido por FOUCAULT, 1970/1996.

14 PÊCHEUX, 1984.

is Ibid., p.263
} 
enunciado ou de uma sequiência coloca necessariamente em jogo (através da detecção de lugares vazios, de elipses, de negações e interrogações, múltiplas formas de discurso relatado...) o discursooutro como espaço virtual de leitura desse enunciado ou dessa seqüência. É este discurso-outro que insiste enquanto presença virtual do interior da materialidade descritível da seqüência, que Pêcheux (1983) vai reconhecer como "lei do espaço social e da memória histórica, logo como o próprio princípio do real sócio-histórico”. Vemos, assim, afirmado o papel estruturante da memória discursiva em relação ao real histórico, ou dito de outro modo, o efeito de retorno que ela produz sobre o real a partir do qual e no qual ela própria se constitui.

Ora, o que caracteriza o funcionamento da memória discursiva como espaço de regularização é o fato de que os efeitos de série ou de repetição que essa regularização produz agem também retroativamente. Assim, conforme Pêcheux (1984, p. 264):

Esta regularização discursiva, que tende a formar a lei da série do legível, é sempre suscetível de afundar sob o peso do acontecimento discursivo novo que vem a perturbar a memória: a memória discursiva tende a absorver o acontecimento, da mesma forma que uma série matemática se prolonga fazendo conjecturas sobre o termo seguinte a partir do engate produzido pela série, mas o acontecimento discursivo ao interrompê-la, pode desarticular ešśa regularização e produzir retrospectivamente uma outra série sob a primeira, pode desmascarar a aparição de uma nova série que não estava ainda constituída e que é, desta forma, produto do acontecimento; neste caso, o acontecimento desloca e desregula os implícitos associados ao sistema de regularização anterior ${ }^{16}$

16 A memória discursiva, tal como definida por Courtine, por ter a linguagem como sua materialidade específica, é afetada pelo equívoco, pela falha. É, portanto, necessariamente lacunar, o que abre um espaço de desdobramentos possíveis a partir da sua afetação pelo acontecimento. Pêcheux (1983a,1983b), Jean Davallon (1984),, Pêcheux et al. (1981) e Orlandi (2001) abrem a possibilidade de se pensar a dicursividade em relação a outras materialidades simbólicas. Apresenta-se, assim, um campo vasto de pesquisa dentro do qual se coloca necessariamente a 
Nesse sentido, Pêcheux (1983a, p.17) define o acontecimento discursivo como o "ponto de encontro de uma atualidade e uma memória". É um elemento histórico descontínuo e exterior que afeta a memória produzindo ruptura e deslocamentos. Assim, pelo funcionamento da memória no acontecimento discursivo, os sentidos produzidos ao mesmo tempo repetem e deslocam o já-dito, produzindo uma projeção e um retorno dos processos discursivos sobre si mesmos, reconfigurando e desestabilizando as séries de repetição, dando lugar a novas interpretações.

Dessa maneira, entendemos o acontecimento discursivo como o lugar material onde o real da língua e o real da história se encontram produzindo uma ruptura, uma interrup̧̧ão e uma emergência nas relações de continuidade definidas pelos rituais enunciativos que conformam as práticas discursivas na sua historicidade, i.e. na determinação do sentido e do sujeito por formações discursivas inscritas no complexo de formações ideológicas. Assim, o acontecimento discursivo produz a ruptura de uma prática discursiva pela transformação dos rituais enunciativos que a definem; a interrupção de um processo de reformulação parafrástica de sentidos pela mudança das condições de produção; a emergência de um enunciado ou de uma posição de sujeito novos que reconfiguram o discurso, e, através deste, participam do processo de produção do real histórico (ZOPPI-FONTANA, 1994; 1997c). O acontecimento discursivo produz efeito de retorno (de deslocamento e desregularização) não só sobre a memória discursiva e as materialidades discursivas que a configuram, mas também sobre os próprios processos históricos e sociais dos quais o discurso participa como prática, agindo eficazmente na reprodução/transformação das relações sociais. É assim que o discurso, enquanto uma das formas materiais da ideologia, se inscreve como força material nas práticas históricas, produzindo (e não só refletindo) o real histórico ${ }^{17}$.

questão de compreender e descrever o funcionamento do equívoco (efeito das contradições históricas) materializado a partir da ordem própria de diferentes sistemas simbólicos.

17 Esta dimensão do discurso é trabalhada por PÊCHEUX, 1975, como eficácia material do imaginário. Cf. também SERCOVICH, 1977; CASTORIADIS, 1986; ZOPPI-FONTANA, 1997c; 1998. 
Em trabalhos anteriores (ZOPPI-FONTANA, 1997c), mobilizamos esta noção para analisar os pontos de quebra de rituais enunciativos já estabilizados e legitimados em determinadas práticas. No presente artigo, analisamos essa dimensão das práticas discursivas em relação ao discurso jurídico, especificamente ao arquivo (FOUCAULT, 1970; PÊCHEUX, 1982; GULLHAUMOU e MALDIDIER, 1994) composto pelos textos legais (resoluções, decretos, leis estaduais e municipais) referentes ao comércio ambulante. Assim, ao pensar o discurso na sua dimensão de acontecimento focalizamos os efeitos de ruptura, de desestruturação-reestruturação, de instabilidade, das redes e trajetos de sentidos que constituem a memória discursiva, dando lugar a novas discursividades nas quais se inscreve o sujeito ${ }^{18}$. Por outro lado, ao considerar o funcionamento do arquivo como dispositivo normalizador/normatizador dos gestos de leitura a partir dos quais se interpretam/produzem os sentidos, refletimos, também, sobre a circulação e legitimação dos sentidos na sociedade e sobre os diversos dispositivos de controle e gestão da memória coletiva.

Arquivo e gestos de leitura

Pêcheux (1982) reflete sobre a relação entre a construção/conservação de arquivos e a divisão social do trabalho de leitura historicamente produzida em relação a sua manipulação/interpretação, configurando gestos de leitura que the estão associados e que funcionam como dispositivos de normatização, legitimação, e autorização da interpretação. $\mathrm{O}$ autor define arquivo "no sentido amplo de campo de documentos pertinentes e disponíveis sobre uma questão",19 e acrescenta:

Seria do maior interesse reconstruir a história deste sistema diferencial dos gestos de leitura subjacentes, na construção do arquivo, no acesso aos documentos e a maneira de apreendê-los, nas práticas silenciosas da leitura "espontânea" reconstituíveis a partir de seus efeitos na escritura: consistiria em marcar e reconhecer as evidências práticas que organizam estas leituras,

\footnotetext{
18 Cf. DORNELES (1999); MiTTMAN (1999); INDURSKY (2003); ZOPPIFONTANA (1997c; 1999a; 1999c).

19 PÊCHEUX, 1982, p.57.
} 
mergulhando a "leitura literal"(enquanto apreensão-dodocumento) numa "leitura interpretativa" - que já é uma escritura. Assim começaria a se constituir um espaço polêmico das maneiras de ler, uma descrição do "trabalho do arquivo enquanto relação do arquivo com ele-mesmo", em uma série de conjunturas, trabalho da memória histórica em perpétuo confronto consigo mesma. ${ }^{20}$

Neste nosso trabalho, gostaríamos de destacar esta relação entre gestos de leitura do arquivo e práticas de escritura como questão que está no cerne do funcionamento do arquivo jurídico na produção de efeitos de normatização/normalização da ordem do social. Para tanto, concordamos com o autor quando afirma que:

É esta relação entre língua como sistema sintático intrinsecamente passível de jogo, e a discursividade como inscrição de efeitos lingüísticos materiais na história, que constitui o nó central de um trabalho de leitura de arquivo ${ }^{21}$

A análise que propomos dos textos legais referentes à presença dos camelôs no espaço público urbano de Campinas se debruça sobre esta materialidade da língua na discursividade do arquivo e, para isso, considera o funcionamento da memória discursiva na estruturação dos enunciados do arquivo jurídico. É justamente porque assumimos que "o gesto de interpretação se faz entre a memória institucional (o arquivo) e os efeitos de memória (interdiscurso), podendo assim tanto estabilizar como deslocar sentidos",22, que diferenciamos, na análise, arquivo jurídico (o conjunto de textos legais pertinentes a nossa questão tal com

Merece destaque aqui o projeto ENDICI (Enciclopédia Discursiva da Cidade) desenvolvido no Laboratório de Estudos Urbanos (LABEURB/UNICAMP) sob a coordenação da Prof. Eni Orlandi, que materializa com sucesso o desejo manifesto por Pêcheux (1982, p. 64) "de construir procedimentos algoritmos informatizados, traduzindo, tão fielmente quanto possível, a pluralidade dos gestos de leitura que possam ser marcados e reconhecidos no espaço polêmico das leitura de arquivos". Cf. ORiANDI, 2003 e www.labeurb.br/endici

21 PÊCHEUX, 1982, p.63.

22 ORLANDI, 1999, p.48. 
organizados pela Biblioteca Jurídica da Prefeitura de Campinas) de memória discursiva.

Orlandi (2003, p.15) distingue memória discursiva de arquivo $^{23}$, definindo este último como memória institucionalizada, estabilização e atestação de sentidos que produz um efeito de fechamento. "Se no interdiscurso há o que se deve dizer mas também o que se pode dizer e mesmo a possibilidade de se dizer o irrealizado, o arquivo repousa sobre o realizado, menos sobre o que pode e muito mais sobre o que dever ser dito"24. Assim, o arquivo, à diferença da memória discursiva, se estrutura pelo não-esquecimento, pela presença, pelo acúmulo, pelo efeito de completude. E pela autoria em relação a práticas de escrita, de legitimação, de documentação, de indexação, de catalogação, de permanência, de acessibilidade. E assim, controle da leitura, dos gestos de leitura e dos trajetos da interpretação. Conforme a autora, "enquanto arquivo, a memória tem a forma da instituição que congela, que organiza, que distribui sentidos. O dizer nessa relação é datado[...] Enquanto interdiscurso, porém, a memória é historicidade, e a relação com a exterioridade alarga, abre para outros sentidos, dispersa, põe em movimento".

É importante destacar aqui o funcionamento da repetição sem modificações do texto legal através das diversas edições de leis e resoluções. Pensamos aqui na repetição formal definida por Orlandi (1996, p. 70) como uma técnica de produzir frases, como exercício gramatical. A autora diferencia este tipo de repetição da repetição empírica (exercício mnemônico) e da repetição histórica (a que inscreve o dizer no repetível enquanto memória constitutiva, saber discursivo, interdiscurso). Para fins de nossa análise, interessa observar o funcionamento da repetição formal no texto legal, que trabalha na constituição de um espaço de memória, que se sustenta no funcionamento do corpo de leis enquanto arquivo jurídico escrito. E aqui podemos lembrar a distinção proposta por Gadet e Pêcheux $(1981 ; 2004)$ entre o direito continental europeu e o direito anglo-saxão. Segundo Pêcheux, o direito continental europeu se reconhece na ordem universal da doutrina que é de natureza dedutiva e silogística: trata-se

23 Esta distinção já é trabalhada em ORLANDI, 1996, 1999. Cf. também ORLANDI, 1997.

24 ORLANDI, 2003, p.15. 
de cobrir o fato singular pela generalidade da lei, isto é, de aplicar uma regra jurídica a fatos já constituídos no espaço do Direito Positivo. Neste caso, segundo o autor, o trabalho da interpretação se reduz a fazer funcionar as fórmulas do texto, sempre as mesmas até um novo ato de escrita que resolva em contrário, para incluir nelas ou excluir delas tal ou qual caso singular. O Direito Oficial no Brasil estaria organizado a partir desses mesmos funcionamentos. Na nossa análise, focamos o funcionamento do arquivo como um dispositivo normatizador da escritura/interpretação dos sentidos da ordem do jurídico e de sua relação com a ordem do social e do político.

Neste sentido, queremos enfatizar o funcionamento do arquivo de textos legais na formação de uma memória que trabalha como espaço de interpretação. É o efeito de reformulação parafrástica da lei se projetando dentro do arquivo, na redação de novos textos legais, e projetando-se sobre os fatos, na construção de uma jurisprudência. O arquivo jurídico funciona, então, pela produtividade do acúmulo, pela ilusão de completude, pelos efeitos de congelamento de uma escritura no tempo. Assim, o arquivo jurídico cristaliza um gesto de leitura que se caracteriza por ser acumulativo, denegativo e estratificado, no sentido de operar por camadas ou estratos sobrepostos, que estabelecem relações textuais de citação/negação e relações interdiscursivas de reformulação/apagamento.

O texto da lei: gestão do arquivo e efeitos de memória

Gostaríamos agora de focalizar a análise no funcionamento do discurso jurídico, enquanto Direito Oficial, isto é, explorar o corpo mais ou menos estruturado e pretendidamente consistente de leis, decretos, portarias, regulamentações e outras peças legais que constituem o campo da Dogmática Jurídica, abarcando todos os ramos do direito positivo. Neste trabalho, não consideramos o campo da jurisprudência dogmática, isto é, da solução dos conflitos singulares determinada nos processos pela interpretação da lei realizada pelos magistrados.

Quando se analisa a legislação municipal sobre o caso dos camelôs, o que surpreende, numa primeira abordagem, é o fato de que a primeira resolução específica regulamentando a presença dos camelôs nas ruas da cidade data de inícios de 1993, embora se remonte a 1974 a criação do órgão que administra e fiscaliza o uso e ocupação do solo público. Este órgão, em Campinas, é a autarquia 
municipal denominada SETEC - Serviços Técnicos Gerais - criada pela Lei Municipal 4369/74. O decreto 5839/79, que dispõe sobre as regras de uso e ocupação do solo público para a instalação de bancas de jornais, revistas e frutas e para o exercício do comércio ambulante, data de 1979.

Neste decreto e nos posteriores que introduzem alterações ou revogam sua vigência, define-se o uso e ocupação do solo público a partir das atividades comerciais realizadas nele através de instalações removíveis ou do comércio ambulante. Em trabalhos anteriores ${ }^{25}$, analisamos o funcionamento dos textos legais que se caracterizam por produzir a estabilização das designações e a reificação da referência em relação à questão dos camelôs e mais amplamente do comércio ambulante. Vejamos, por exemplo, o recorte a seguir ${ }^{26}$ :

1 - À SETEC compete: 1- administrar e fiscalizar por delegação a ocupação do solo em vias e logradouros públicos. (Lei 4369/74, artigo 3,1$)$

2 - À SETEC compete ainda: 1 - autorizar o uso do solo para fins de exercício do comércio em instalaçōes removíveis em geral, nas vias e logradouros públicos, ou para o exercício do comércio ambulante eventual ou não, fixando os respectivos locais. (Lei $4369 / 74$, artigo 4,1 )

3 - Entende-se por comércio ambulante as saídas de mercadorias do estabelecimento, sem destinatário certo, por meio de veículos motorizados, carrinhos manuais, cestas, tabuleiros e qualquer outro meio para vender ao consumidor ou usuário final. (Decreto $5839 / 79$, art. 2, 2)

4- CAPÍTULO I - Da utilização do solo público. Artigo 1 Considera-se comércio em solo público aquele exercido em instalações removíveis, nas seguintes categorias:

I - Feiras livres;

II - Bancas em geral;

III - Ambulantes.

Parágrafo único - Na categoria de ambulantes serão incluídos os veículos motorizados, veículos de tração animal, carrinhos manuais, trailers, cestas, tabuleiros, sacolas, malas e qualquer

\footnotetext{
25 Cf. Zoppi-Fontana, (1997a, 1999a, 1999b, 2003)

26 Retomo aqui análises apresentadas em ZOPPI-FONTANA, $1999 \mathrm{~b}$.
} 
outro meio de venda ao consumidor ou usuário final que não se enquadre nos demais itens. (Decreto 7725/83)

É interessante observar o deslizamento que se produz na legislação entre as categorias de uso do solo público / comércio ambulante. Este deslizamento é efeito da força do pressuposto que sustenta a designação do espaço público como SOLO; isto é, como superfície ocupável por meio de edificações ou instalações.

Na Lei 4369/74, o "comércio ambulante" é apresentado como sendo uma das modalidades de utilização do solo público, distinguindo-se do "comércio em instalações removíveis". Assim, no Decreto 5839/79, o tipo de instalações usadas no comércio ambulante são definidas como meios de exercer essa atividade, ou seja, são os instrumentos utilizados para o exercício desse comércio, e, enquanto instrumentos, se diferenciam das instalações removíveis.

Já no Decreto 7725/83, e nos promulgados em anos posteriores regulamentando o uso e a ocupação do solo público, o que era apresentado como meio ou instrumento sofre um processo de reificação, sendo apresentado como a categoria mesma de "comércio ambulante". "Ambulantes" é um tipo de instalação removível: "Considera-se comércio em solo público aquele exercido em instalações removíveis...Na categoria de ambulantes serão incluídos os veículos motorizados, veículos de tração animal, carrinhos manuais, trailers, cestas, tabuleiros, sacolas, malas e qualquer outro meio de venda ao consumidor ou usuário final que não se enquadre nos demais itens" 27 . É o próprio meio que é categorizado como ambulante e não a atividade (o comércio) que é exercida por meio dele. Este deslizamento permite acrescentar, de um decreto para outro, novas distinções na categoria de comércio em instalações removíveis, opondo a modalidade "ambulantes" a outras modalidades definidas pelo tipo de instalação de que se trata: "feiras livres, bancas em geral, quiosques, trailers, tabuleiros".

Desta maneira, as categorizações do espaço da cidade são feitas com base nas instalações edificadas ou colocadas sobre ele e não

27 Usamos aspas para sinalizar os casos em que utilizamos designações presentes nos textos legais e jornalísticos analisados. 
em relação aos sujeitos que o habitam ou as práticas desses sujeitos ${ }^{28}$. A categoria de "terreno edificável ou ocupável" funciona como pressuposto que fixa os processos de designação no termo técnico SOLO. Efetivamente, é a designação SOLO a que serve de base para a construção das distinções jurídico-administrativas que regulamentam a inserção legal do sujeito no espaço público urbano. Essas distinções são produzidas no funcionamento do arquivo jurídico a partir da tensão contraditória entre categorias definidas legalmente como nomenclaturas" ${ }^{29}$ : "ambulante/ comércio ambulante /comércio em instalações removíveis", e a aparição ou emergência de novas designações que irrompem como efeito de pré-construído $o^{30}$ : "camelôs/ trabalhadores da economia informal /comércio informal", que funcionam como indícios de uma ordem de discurso exterior ao arquivo jurídico mas presente nos seus efeitos de heterogeneidade.

Observamos, assim, o funcionamento do arquivo jurídico produzindo efeitos de estabilização referencial como resultado da repetição formal dos enunciados que são reformulados de um decreto a outro com ínfimas alterações. Importa destacar, também, o funcionamento da definição como dispositivo de escritura do texto legal. Nunes (2003), ao analisar a definição lexicográfica, considera a relação entre o dito na definição e os não-ditos que intervêm nela de diversas formas. $\mathrm{O}$ autor afirma:

Vale lembrar aqui a definição legal de comércio ambulante através da qual a Prefeitura da cidade de São Paulo regulamentou o exercício local dessa atividade: "Comércio ambulante constitui atividade regular e habitual que atende a necessidades da população" (Decreto 27660 de 2302-89) No mesmo decreto se considera "vendedor ou prestador de serviços nas vias públicas a pessoa física civilmente capaz, que exerça atividade lícita, sem relação de emprego e por conta própria, em caráter precário". Comparando as duas legislações municipais, percebe-se mais nitidamente o processo de reificação/objetificação presente nos textos legais de Campinas e seus efeitos sobre os processos discursivos de identificação/subjetivação que constituem os sujeitos na sua relação com

29 a cidade que habitam.

GADET, F.; PÊCHEUX, M. (1981/2004, p.189-190). Neste trabalho, consideramos nomenclaturas as categorias que são nomeadas e definidas juridicamente pelos textos legais configurados como arquivo. 
Há uma memória lexicográfica que é retomada, denegada, atualizada. O conceito de interdiscurso faz com que a definição não seja vista como um enunciado isolado, homogêneo, autônomo. O valor significativo do enunciado definidor só se estabelece na relação com o conjunto de enunciados que estruturam o interdiscurso, quer dizer, na relação com o campo da memória do dizer. $^{31}$

Deslocando a reflexão do autor para nosso campo, almejamos, nós também, mostrar, com a análise dos enunciados definidores dos textos da lei, as filiações discursivas que configuram o campo de memória do discurso jurídico e que determinam o enunciável do arquivo jurídico em determinadas condições de produção.

Desta maneira, observamos um outro silenciamento ${ }^{32}$ produzido pelo funcionamento do arquivo jurídico na sua repetição: ele silencia o fato de os camelôs se constituírem no espaço da cidade como sujeitos. A designação do espaço urbano como solo focaliza os processos de referenciação nos objetos que o ocupam, silenciando a existência dos sujeitos que o praticam. Observe-se que na formulação dos decretos, o agente da ação, exprimida pelos verbos nominalizados, fica implícito: não se identificam nem se mencionam os sujeitos que exercem o comércio em solo público ("para fins de exercício do comércio em instalações removíveis em geral"; "para o exercício $<$ por $\emptyset>$ do comércio ambulante eventual ou não"; "considera-se comércio em solo público aquele exercido <por $\emptyset>$ em instalações removíveis"). Não sendo considerados os sujeitos (ambulantes), o debate sobre seus direitos (à cidade) ficam banidos da pauta de discussão e da legislação. Dessa maneira, silenciam-se enunciados que definem os camelôs enquanto sujeitos sociais específicos e diferenciados.

Encontramos, assim, no funcionamento da lei, um processo de reformulação parafrástica fortemente ancorado na repetição formal dos enunciados, que se caracteriza por produzir um efeito de reificação/objetificação do espaço público e dos cidadãos através da definição legal de categorias/nomenclaturas. Nesse sentido, pela força

31 NUNES, 2003, p.14. Cf., também, MAZIÈRE, 1989.

32 Para uma reflexão sobre o silêncio como constitutivo dos processos de produção do sentido, cf. ORLANDI , 1992, 
institucional do direito, os camelôs não só são apagados, mas são condenados à inexistência jurídico-administrativa. Vale a pena lembrar aqui a epígrafe com que iniciamos o nosso texto, na qual Gadet e Pêcheux apontam para o fato de que na ordem universal do Direito Positivo (compreendido como discurso doutrinal), a nomenclatura das categorias jurídicas "constitui por seu sistema de sanções ao mesmo tempo um modelo de organização social e um dispositivo moral de formação dos comportamentos"33. Perversa eficácia dos enunciados do arquivo jurídico que projetam assim sua força de enquadramento sobre a cidade, invisibilizando (condenando à inexistência formal) práticas históricas de sujeitos concretos que constituem com seus movimentos o real urbano na sua potencialidade de desorganização do Direito ${ }^{34}$.

É importante destacar aqui o funcionamento da repetição sem modificações do texto legal através das diversas edições de leis e resoluções: a repetição formal (ORLANDI, 1996) do texto legal trabalha na constituição de um espaço de memória, que se sustenta no funcionamento do corpo de leis enquanto arquivo jurídico escrito. Configura-se, assim, pela repetição, um gesto de leitura fechado, homogêneo, auto-referencial, que funciona em um movimento de contínuo retorno literal sobre o já escrito para repeti-lo formalmente. Gesto de leitura no/do arquivo jurídico que desconhece um seu exterior, que apaga a referência a discursos outros, que se concentra sobre si mesmo, estabelecendo uma rede interna de citações datadas, de referências intertextuais precisas, que produzem um efeito de completude do corpo de leis que constituem o arquivo. Gesto de leitura que se projeta sobre as práticas institucionalizadas de escritura legal, normatizando um dizer circular, auto-referencial, que desconhece/esquece constitutivamente enunciados produzidos fora do arquivo.

Neste sentido, queremos enfatizar o funcionamento do arquivo de textos legais na formação de uma memória que trabalha como espaço de interpretação: trata-se do funcionamento dos processos de

33 GADET, F. e M. PÊCHEUX (op.cit., p. 190).

${ }^{34}$ É só em 1993 e depois da formação do Sindicato dos Trabalhadores na Economia Informal, que se reconhecerá juridicamente, com a Resolução 05/93, a existência dos camelôs na cidade e a necessidade de uma legislação específica. 
paráfrase sedimentando um gesto de interpretação ${ }^{35}$. Retomando as colocações teóricas realizadas no início deste trabalho, podemos observar na permanência deste processo de reificação, o efeito da memória constituindo um espaço de regularização da materialidade discursiva, construindo a "lei" da série do legível, série pautada pela interpretação reificadora do espaço público urbano e objetificadora de seus sujeitos. Também salientamos que essa "lei" que faz série (i.e. que configura as reformulações dos enunciados do arquivo jurídico de um texto a outro ao longo do tempo) se sustenta no silenciamento de outros enunciados exteriores ao arquivo legal, que autorizam/legitimam outros gestos de interpretação para a questão. Sendo silenciados, esses enunciados funcionam como presença ausente, quer dizer, pela falta. $\mathrm{O}$ desafio que se apresenta ao analista na sua leitura é descrever o funcionamento discursivo desses enunciados/elementos de saber ausentes, confrontando o arquivo (memória institucionalizada, controlada, saturada) com o interdiscurso (memória discursiva constitutiva, não apreensível nem aprendida, lacunar, falha). Por outro lado, interessa mapear a aparição de acontecimentos discursivos que venham a desregularizar a série de repetições formais, introduzindo prospectiva e retrospectivamente um novo gesto de interpretação.

Para tanto, vamos observar o funcionamento da Resolução 05/93 da Setec, que é o primeiro texto legal específico do município de Campinas regulamentando a prática dos camelôs. A originalidade da sua redação merece uma análise especial:

RESOLUÇÃO 05/93 - DISCIPLINA E REGULAMENTA O COMÉRCIO DESENVOLVIDO PELOS TRABALHADORES DA ECONOMIA INFORMAL

O Exmo. Sr. Presidente da SETEC-Serviços Técnicos Gerais no uso das atribuições de seu cargo, conferidas pelo disposto nos incisos I e III do artigo $8^{\circ}$ da Lei Municipal n 4369 de 11 de fevereiro de 1974, e

Considerando que é de competência desta autarquia disciplinar o comércio do solo público na cidade de Campinas nos termos do inciso I do artigo $3^{\circ}$ da Lei Municipal n 4369/74;

35 Entendemos gesto de interpretação no sentido definido por ORLANDI (1996, p.200) como ato simbólico que intervém no real do sentido. 
Considerando que a atividade exercida pelos "camelôs" de forma desordenada, tem ocasionado problemas na área central da cidade, gerando conflitos entre comerciantes legalmente. estabelecidos

Considerando que a atividade atípica dos "camelôs" é também consequiência da grave crise econômica que atravessa o país;

Considerando, finalmente, que cabe ao poder público, amenizar os graves problemas sociais enfrentados pela população,

RESOLVE:

ARTIGO 1: - Fica permitida a utilização do solo público, a título precário, aos trabalhadores do comércio da economia informal, exclusivamente nas áreas previamente demarcadas pela autarquia no Terminal Miguel Vicente Cury (Terminal Central) e Rua Álvarez Machado, entre rua General Osório e Av. Campos Sales; $[\ldots]$

ARTIGO 5: - Fica proibida a permanência e a comercialização de trabalhadores do comércio da economia informal de que trata a presente Resolução, em quaisquer outros locais do Município de Campinas, com exceção da área já implantada que circunda o Terminal Central do Mercado Municipal.

[...]

ANEXO- REGULAMENTO DE COMERCIALIZAÇÃO DE TRABALHADORES DA ECONOMIA INFORMAL DE CAMPINAS - SP.

I - DAS INSCRIÇÕES

1.1. - Os interessados na exploração do solo público, com comércio informal, deverão requerer sua inscrição junto à SETEC...

1.2. - As inscrições serão deferidas prioritariamente aos trabalhadores que já exploram atividade nesta data e que residam no município de Campinas;(...)(grifos nossos)

A Resolução 05/93 se diferencia da legislação anterior pelo fato de considerar separadamente o caso específico dos camelôs. Em relação à série de textos legais anteriores, observamos que o texto da resolução já não refere a "ambulantes" de maneira genérica enquanto subcategoria da categoria mais geral e abrangente de "comércio ambulante". No texto da resolução, encontramos designações específicas que se aplicam unicamente ao caso dos camelôs; elas são 
"trabalhadores da economia informal", "comércio informal" (que reproduzem as designações mobilizadas pelo discurso do sindicato) e "camelôs" (entre aspas no texto legal, que reproduz, assim, tomando distância, a designação mais utilizada pela população em geral, pela mídia e pelos próprios interessados). Observamos, portanto, a ruptura da série de repetições anteriores, através de um deslocamento na determinação (de comércio ambulante para comércio informal) e da emergência de uma designação nova para o arquivo jurídico (trabalhadores da economia informal).

A ruptura que esta Resolução produz na memória discursiva se dá, também, pela categorização do uso do solo público a partir da prática ("a exploração do solo público com comércio informal"), reconhecida como legítima ("as inscrições serão deferidas prioritariamente aos trabalhadores que já exploram atividade nesta data"), de indivíduos claramente identificados como sujeito coletivo ("trabalhadores do comércio da economia informal") [grifos nossos].

Queremos chamar a atenção para a emergência no arquivo jurídico da determinação de informalidade que permite o deslocamento das designações de "comércio ambulante" para "comércio informal" e "comércio da economia informal". Trata-se do efeito sobre os enunciados do arquivo de elementos de saber exteriores que entram como efeito de pré-construído, alterando o regime de enunciabilidade estabilizado no arquivo pela série de repetições formais e reformulações parafrásticas. Com efeito, os textos da lei passam a sofisticar as distinções que esquadrinham o espaço e os sujeitos urbanos, acolhendo além das categorias de legal/ilegal/clandestino (próprias do gesto de leitura/escritura normalizador/normatizador do arquivo legal), a designação de diversas modalidades de existência como "rcgular/irregular/informal", que reconhecem a ordem do social intervindo na estruturação da cidade. Muda assim o gesto de interpretação do social pelo jurídico, que passa a ter que lidar com modalidades de existência definidas materialmente na ordem do social e no fogo da luta política pelos direitos e que não se enquadra na modalidade de existência formal que define o funcionamento das categorias jurídicas no arquivo jurídico. A materialidade da cidade e suas práticas invadem os frios espaços da formalidade/formalização da lei produzindo equívocos e 
deslocamentos em um espaço discursivo que se quer/simula ser logicamente estabilizado ${ }^{36}$.

Estes funcionamentos fazem com que a Resolução 05/93 se institua no arquivo como acontecimento, abrindo um novo espaço de regularização da materialidade discursiva: os novos textos legais vão retomar a partir de então esses funcionamentos. Veja-se, por exemplo, a resolução de 29 de dezembro de 1994, que "Dispõe sobre a proibição de instalação de ambulante nas proximidades do santuário Nossa Senhora de Guadalupe". Nesta resolução, o equívoco das designações afetadas pela materialidade do acontecimento discursivo leva o texto legal a fazer a distinção entre "equipamentos para comércio", "ambulantes" e "camelôs", o que já sinaliza o aparecimento de uma nova série de regularização do arquivo:

Considerando que a Associação de Moradores do Jardim Garcia, requereu através de abaixo assinado a preservação da área, com a proibição de instalação de equipamentos, ambulantes e camelôs. RESOLVE: artigo 1 - Fica proibida a instalação de qualquer equipamento para comércio, ambulantes e camelôs, na área que compreende...(grifos nossos).

Em agosto de 1997, uma nova resolução, a número 09/97, é promulgada pelo presidente da SETEC. Esta nova Resolução, que revoga a resolução 05/93, já funciona afetada pelo acontecimento daquela resolução que vem substituir. Nesse sentido, encontramos nela a repetição formal da designação "Trabalhadores da Economia Informal", o que sinaliza sua relação de paráfrase com a série aberta em 1993 e o apagamento da série anterior. Com efeito, a partir desta designação, o texto legal não recupera o processo de reificação dos sujeitos que atuam no espaço público (característica da série anterior à Resolução 05/93), mas focaliza a regulamentação na regulamentação de uma prática (de fato) de sujeitos já reconhecidos como legítimos.

Considerando o grande número de trabalhadores da Economia Informal, exercendo o comércio no Terminal Central nas áreas de frente e fundos; na rua Benedito Cavalcante Pinto, entre os nº 297 e 303 e Rua Álvarez 
Machado nos trechos compreendidos entre as Ruas Dr. Costa Aguiar e Ferreira Penteado e Ruas Bernardino de Campos e Dr. Campos Salles.

Considerando que recentemente houve recadastramento desses trabalhadores junto à SETEC.

Considerando a necessidade de regulamentar o comércio exercido pelos trabalhadores da Economia Informal naqueles locais;

RESOLVE: (grifos nossos) ${ }^{37}$

É importante também considerar o funcionamento da Resolução 05/93 enquanto acontecimento discursivo, não só em relação à nova série de regularização da memória que ela possibilita, mas também em relação à série anterior, mostrando retroativamente o que nela faltava, isto é, os esquecimentos necessários que o processo de reificação/objetificação produzia em relação às possibilidades de interpretação do espaço público urbano.

Nesse sentido, interessa destacar que se, por um lado, a nova série, ao contrário dos textos legais anteriores, explicita, pela emergência de novas designações, a existência de sujeitos sociais diferenciados ("trabalhadores da economia informal", "camelôs", "comércio informal"), por outro lado, nem a Resolução 05/93 nem as seguintes definem formalmente estas novas categorias sobre as quais se legisla. As novas designações irrompem no arquivo como efeito de pré-construído, isto é, como um objeto pensado antes, em outro lugar, independentemente do enunciado onde aparece atualmente (PÊCHEUX, 1975). Dessa maneira, o texto legal aponta, pela falta, a um outro discurso, exterior à circularidade do arquivo legal, mas presente na memória discursiva como espaço do confronto. São as designações (e consequientemente, os objetos discursivos) trabalhados historicamente pela prática discursiva e política do sindicato, que emergem no texto legal, desestabilizando os processos de designação e interpretação do espaço público já sedimentados como evidência.

37 Outro indício que sinaliza a emergência de uma nova série de regularização/estruturação discursiva é a presença de considerandos nos textos legais a partir da Resoluçào 05/93. Cf. ZOPPI-FONTANA (1999b) para uma análise do processo de particularização produzido como efeito do funcionamento dos considerandos no arquivo jurídico. 
Dessa forma, a Resolução 05/93, enquanto acontecimento no arquivo, desnaturaliza o efeito de completude do texto legal, revelando o caráter lacunar de toda memória que só se fecha imaginariamente através de processos de institucionalização dos gestos de leitura e escritura do arquivo.

A Resolução 05/93 permite mostrar, num mesmo texto, os efeitos da relação contraditória que se estabelece entre arquivo e acontecimento discursivo. Por um lado, o arquivo funciona como espaço de sedimentação de uma memória hegemônica que fornece as evidências sobre o direito dos sujeitos à cidade ${ }^{38}$; por outro lado, o acontecimento irrompe como ruptura na série parafrástica de reformulações dos textos legais, produzindo um deslocamento nas filiações históricas que possibilitam a interpretação, permitindo, desta maneira, a emergência de outras memórias na definição do espaço público urbano.

Efeitos do arquivo na textualização do político

Com as análises apresentadas neste trabalho pretendemos mostrar o funcionamento das práticas discursivas da instância jurídicoadministrativa do Município que intervêm no espaço da cidade como suporte imaginário da gestão/organização do real urbano. A partir da análise de um arquivo específico (o arquivo jurídico referente à prática de comércio no espaço público urbano), desenvolvemos uma reflexão sobre a relação entre arquivo, memória e acontecimento discursivos, trabalhados tanto teórica quanto analiticamente. Dessa maneira, almejamos contribuir para o estudo da lei no seu funcionamento social e, especificamente, do arquivo jurídico como dispositivo de gestão da memória coletiva. Dispositivo que funciona produzindo silenciamentos que percorrem a linha de confronto das posições de sujeito que representam, no interdiscurso, as lutas políticas e ideológicas que dividem o social e que definem a distribuição/regulamentação do direito à cidade.

Vale lembrar aqui a reflexão desenvolvida por Lima (2002, p.14) no seu trabalho sobre o processo constituinte brasileiro de 1988. $\mathrm{O}$ autor afirma que:

38 Cf. LEFEVBRE (1968/1980). 
A Constituição burguesa é o arcabouço jurídico fundamental através do qual a classe burguesa estrutura e delimita as instituições e mecanismos de ação legal do Estado burguês. Através da definição das "regras do jogo" político, da delimitação de direitos e deveres do cidadão, ela serve de instrumento pelo qual o Estado burguês procura institucionalizar os conflitos e limitar e exercer controle sobre a luta entre classes sociais. Neste sentido, as questões constitucionais estão relacionadas diretamente com as questões de poder de Estado [...] Por isso, [a Constituição] exerce não só um papel jurídico mas também político e ideológico, que é dissimulado através da primazia dada ao papel jurídico desempenhado por ela. [...] Ela é a estruturação jurídica da dominação burguesa, mas, também, carrega no seu conteúdo o produto histórico de uma determinada correlação de forças existentes entre as classes sociais em luta num determinado momento histórico, numa determinada sociedade. [...] A constituição que é feita sob clara hegemonia ou dominância de uma ou mais classes, objetiva tornar perene este momento de produção da legislação, visa estabilizar, congelar esse momento histórico, criando regras que dificultem sua modificação. Neste sentido, ela não é um simples registro do presente, mas também uma tentativa de fixação do futuro.

Acreditamos que esta descrição da elaboração e funcionamento do texto constitucional se aplica igualmente a todo o corpo de textos legais que organizam, a partir das diversas instituições político-jurídicas do Estado, as práticas sociais dos cidadãos. Neste sentido, a legislação municipal atua, também, como registro do presente e controle sobre a luta entre classes, o que nos permite pensar o arquivo jurídico como dispositivo normatizador/normalizador da ordem do social sobre a qual se aplica como grade interpretativa logicamente estabilizada. Dispositivo que, pelo silenciamento de gestos de interpretação produzidos em ordens discursivas exteriores ao arquivo jurídico, se projeta sobre o futuro em uma tentativa de fixar o processo histórico em um eterno presente formal. Dessa forma, o arquivo jurídico se constitui no nosso Estado de Direito Positivo como um dos principais dispositivos de gestão da memória coletiva, 
invisibilizando a ordem do político que estrutura, do exterior, a aparente necessidade lógica dos gestos de leitura e escritura da lei.

Courtine (1989) considera os discursos doutrinários como "lugares de memória". Conforme o autor, eles permitem a construção e continuidade de identidades coletivas, sendo a garantia de sua perpetuação através do levantamento, transcrição, organização e inscrição, no arquivo e nos sujeitos, dos traços dessas identidades. $\mathrm{O}$ autor situa o discurso político dentro do conjunto dos discursos doutrinários das sociedades contemporâneas e o aproxima do discurso religioso e do discurso jurídico. O próprio desses discursos é que eles permitem ao sujeito se inscrever em uma genealogia, se reconhecer em uma filiação, retomar um regime de enunciabilidade que garante sua legitimidade. Discursos disponiveis que projetam sobre o sujeito e sobre o real histórico seu poder de categorização, definição, classificação, estabilização das contradições. É neste sentido que entendemos o funcionamento do arquivo jurídico como discurso doutrinário. Como espaço de memória institucionalizada, controlada, cristalizada, que fixa um gesto de leitura estruturado pelo apagamento, pelo silenciamento necessário do seu exterior. Como já dissemos no início deste trabalho, o arquivo jurídico se estrutura pela presença, pelo acúmulo, pelo efeito de completude, pela circularidade, pela auto-referencialidade de seus enunciados. E por práticas de escritura, de legitimação, de documentação, de indexação, de catalogação, de permanência, de acessibilidade. Dessa forma, se configura, na nossa formação social, como uma tentativa de cristalização da história, de fixação da errância dos sujeitos, de normalização da deriva dos sentidos, de prevenção dos movimentos do social.

Porém, a história impõe sua presença inescapável e contraditória, irrompendo com força no acontecimento discursivo que quebra a "lei" do legível (re)produzida no arquivo, fazendo emergir o irrealizado (do político, do social, do jurídico) nas fendas abertas pelo equívoco da língua materializada como escrita jurídica. 
Referências

ACHARD, Pierre. Memória e produção discursiva do sentido. In: P. Achard et al. Papel da Memória. Trad: José Horta Nunes. Campinas: Pontes, 1999. (versão original 1994)

ALTHUSSER, Louis. Ideologia e aparelhos ideológicos do Estado. São Paulo: Martins Fontes, 1973.

ANGENOT, Marc. Le discours social: problématique d'ensemble. Cahiers de recherche sociologique: Le discours social et ses usages. vol.2, $\mathrm{n}^{\circ} 1$, abril 1984

CASTORIADIS, Cornelius. A Instituição Imaginária da Sociedade. Rio de Janeiro: Paz e Terra, 1986

COURTINE, Jean-Jacques. Quelques problèmes théoriques et méthodologiques en analyse du discours; à propos du discours communiste adressé aux chrétiens. Langages 62, p.9-127, 1981.

COURTINE, Jean-Jacques. Définitions d'orientations théoriques et construction de procédures en analyse du discours. Philosophiques, v.9, n.2, p. 239-64, 1982.

COURTINE, Jean-Jacques. Chroniques de l' oubli ordinaire. Sediments, 1. Montreal, 1986.

COURTINE, Jean-Jacques. Présentation de dossier de Thèse d'Etat sur travaux. Corps et discours: elements d'histoire des pratiques langagieres et expressives. Nanterre: Univeristé de Paris X-Nanterre,
jan/1989.

COURTINE, Jean-Jacques. Le tissu de la mémoire: quelques perspectives de travail historique dans les sciences du langage. Langages, n. 114, p. 5-12, junho 1994.

DAVALLON, Jean. A imagem, uma are de memória? In: P. Achard et al. Papel da Memória. Trad: José Horta Nunes. Campinas: Pontes, 1994/1999.

DORNELES, Elizabeth. O discurso do MST: um acontecimento na estrutura agrária brasileira. In: FERREIRA, M.C.L. e F. INDURSKY. Os múltiplos territórios da Análise do Discurso. Porto Alegre: SagraLuzzatto, 1999.

FOUCAULT, Michel. A Arqueologia do Saber. Trad. Luiz Baeta Neves. Rio de Janeiro: Forense Universitária, 1987. 
FOUCAULT, Michel A ordem do Discurso. São Paulo: Edições Loyola, 1996.

FUCHS, C. \& M. PÊCHEUX. A propósito da Análise Automática do Discurso: Atualização e Perspectivas. Trad. Péricles Cunha. In: GADET F. \& T. HAK (ed.) Por uma Análise Automática do Discurso. Uma Introdução à Obra de Michel Pêcheux. Campinas: Ed. da Unicamp, 1990.

GADET, F e M. PÊCHEUX. La langue introuvable. Paris: François Maspero. 1981. Trad: Bethânia Mariani e M. Cláudia Gonçalves de Mello. A línuga inatingivel. Campinas: Pontes, 2004.

GUILHAUMOU, Jacques. La langue politique et la Révolution Française. De l'événement à la raison linguistique. Paris: Méridiens Klincksieck, 1989.

GUILHAUMOU, Jacques. \& D. MALDIDIER. Da Enunciação ao Acontecimento Discursivo em Análise do Discurso. Trad. Freda Indursky. In: GUIMARÃES, Eduardo (ed.). História e Sentido na Linguagem. Campinas: Pontes, 1989.

GUILHAUMOU, J.; D. MALDIDIER \& R. ROBIN. Discours et archive. Experimentations em analyse du discours. Paris: Mardaga, 1994.

GUIMARÃES, Eduardo R.J. Os limites dos sentidos. Campinas: Pontes, 1995.

GUIlHaumou, Jacques.. Semântica do Acontecimento. Campinas: Pontes, 2002.

GUIMARÃES, E. \& E. ORLANDI. Unidade e Dispersão: uma Questão do Texto e do Sujeito. In: ORLANDI, Eni. Discurso e Leitura. São Paulo: Cortez/Campinas: Ed. da Unicamp, 1988.

GUIMARÃES, E. e E. ORLANDI (org.). Língua e cidadania. Campinas: Pontes, 1996.

HAROCHE, Claudine. Fazer Dizer, Querer Dizer. Trad. Eni P. de Orlandi. São Paulo: Hucitec, 1992.

HENRY, Paul. A Ferramenta Imperfeita. Língua, Sujeito, Discurso. Trad. M. Fausta Pereira de Castro. Campinas: Ed. da Unicamp, 1992. 
HENRY, Paul. Os Fundamentos Teóricos da Análise Autmática do Discurso de Michel Pêcheux (1969). Trad. Bethânia S. Mariani. In: GADET F. \& T. HAK (ed.) Por uma Análise Automática do Discurso. Uma Introdução à Obra de Michel Pêcheux. Campinas: Ed. da Unicamp, 1990.

INDURSKY, Freda. A fala dos quartéis e as outras vozes. Campinas: Ed. da Unicamp, 1997.

INDURSKY, Freda. Lula lá: estrutura e acontecimento. ORGANON, v.17, n.35, p.101-122, jan/dez 2003.

LABEURB. O sentido do público no espaço urbano. Projeto temático de pesquisa coordenado pela Profa. Dra. Eni P. de Orlandi, desenvolvido no Laboratório de Estudos Urbanos (LABEURB), no Núcleo de Desenvolvimento da Criatividade (NUDECRI), UNICAMP. Campinas/SP, FAPESP 96/4136-7, 1996.

LAGAZZI-RODRIGUES, Suzy. O desafio de dizer não. Campinas: Pontes. 1988.

LANGAGES, Mémoire, histoire, langage. n. 114. J-J. Courtine (ed.). Paris: Larousse, 1994

LEFEVBRE, Henry. 1968. Le droit à la ville. suivi de Espace et Politique. Paris: Éditions Anthropos, 1980

LIMA, Luziano P.M. de. A atuaçào da esquerda no processo constituinte: 1986-1988. Dissertação de Mestrado. Campinas, Instituto de Filosofia e Ciências Humanas, 2002.

MAINGUENEAU, Dominique. Novas Tendências em Análise do Discurso. Trad. Freda Indursky. Campinas, Pontes, 1989.

MALDIDIER, Denise. (Re)lire Michel Pêcheux aujourd'hui. In: L'inquietude du discours. Paris: Éditions des Cendres, 1990.

MARIANI, Bethânia. S.C. O PCB e a imprensa. Os comunistas no imaginário dos jornais 192-1989. Rio de Janeiro: Editora Revan/ Campinas: Ed. da Unicamp, 1998.

MARIANI, Bethânia. Questões sobre a solidariedade. Orlandi, Eni (org.). Cidade Atravessada. Campinas, Pontes, 2001.

MAZIÉRE, Francine. O enunciado definidor: discurso e sintaxe. Guimarães, E. (org.). História e sentido na linguagem. Campinas. Pontes, 1989. 
MITTMAN, Solange. Nem lá, nem aqui: o percurso de um enunciado. In: FERREIRA, M.C.L. e F. INDURSKY. Os múltiplos territórios da Análise do Discurso. Porto Alegre, Sagra-Luzzatto, 1999.

NUNES, José Horta. Formação do leitor brasileiro. Campinas, Ed. da Unicamp, 1994

NUNES, José Horta. Definição lexicográfica e discurso. Línguas e instrumentos lingüísticos, n.11, p.9-30, jan-jun 2003.

ORLANDI, Eni P. de. As formas do Silêncio. No movimento dos Sentidos. Campinas: Ed. da Unicamp, 1992.

ORLANDI, Eni P. de Interpretação: autoria, leitura, efeitos do trabalho simbólico. Petrópolis: Vozes, 1996.

ORLANDI, Eni P. de Análise do Discurso: princípios $e$ procedimentos. Campinas: Pontes, 1999.

ORLANDI, Eni P. de. Discurso e Texto. Formulação e circulação dos sentidos. Campinas: Pontes, 2001.

ORLANDI, Eni P. de (ed.). Discurso Fundador. A Formação do País e a Construção da Identidade Nacional. Campinas, Pontes, 1993.

ORLANDI, Eni P. de (ed.). Cidade atravessada. Os sentidos públicos no espaço urbano. Campinas: Pontes, 2001.

ORLANDI, Eni P. de (ed.). Para uma enciclopédia sobre a cidade. Campinas: Pontes, 2003.

PAYER, Maria. Educação Popular e Linguagem. Reprodução, confrontos e deslocamentos de sentidos. Campinas: Ed. da Unicamp, 1993.

PAYER, Maria. Memória da língua. Imigração e nacionalidade. Tese de doutorado. Instituto de Estudos da Linguagem, Unicamp, 1999.

PÊCHEUX, Michel. Análise Automática do Discurso. Trad. Eni P. de Orlandi. Em: F. Gadet \& T. Hak (orgs) Por uma Análise Automática do Discurso. Uma Introdução à Obra de Michel Pêcheux. Campinas, Ed. da Unicamp, 1990.

PÊCHEUX, Michel. Semântica e Discurso. Uma Crítica à Afirmação do Óbvio. Trad. Eni P. de Orlandi et alii. Campinas, Ed. da Unicamp, 1988. 
PÊCHEUX, Michel. Rôle de la mémoire. P. Achard, M.P. Gresnais, (eds.) Histoire et Linguistique. Paris: Ed. du CNRS 1984. Tradução ao português: José Horta Nunes. Papel da Memória. Campinas: Pontes, 1999.

PÊCHEUX, Michel. Delimitações, Inversões, Deslocamentos. Trad. José H. Nunes. Cadernos de Estudos Lingüísticos, n. 19, p. 7-24, 1991.

PÊCHEUX, Michel. Ler o arquivo hoje. In: ORLANDI, Eni (ed.). Gestos de Leitura: da história no discurso. Campinas: Ed. da Unicamp, 1994, pgs.55-67.

PÊCHEUX, Michel. O discurso: Estrutura ou Acontecimento. 1983a Trad: Eni P. de Orlandi. Campinas: Pontes, 1990.

PÊCHEUX, Michel. Lecture et mémoire: project de recherche. 1 "ed. 1983b. In: L'inquietude du discours. Paris: Ed. des Cendres, 1990.

PÊCHEUX, $M$ et alii. La frontière absente (un bilan). In: Matérialités discursives. Lille: Presses Universitaires de Lille, 1981.

RANCIÈRE, Jacques. O desentendimento. Política e Filosofia. Trad. Ângela Leite Lopes. São Paulo: Editora 34, 1996.

SERCOVICH, A. El discurso, el psiquismo y el registro imaginario. Ensayos semióticos. Buenos Aires: Nueva Visión, 1977

ZOPPI-FONTANA, Mónica. Camelôs e o direito à cidade. In: Anais do $7^{\circ}$ Encontro da Anpur: Novos recortes territoriais, novos sujeitos sociais: desafios ao planejamento. Recife, MDU/UFPE, p.1160- 1179, $1997 \mathrm{a}$.

ZOPPI-FONTANA, Mónica. O sentido público no espaço urbano. RUA, Revista do Núcleo de Desenvolvimento da Criatividade, n. 3, p.149-154, 1997b.

ZOPPI-FONTANA, Mónica. Cidadãos modernos. Discurso $e$ representação política. Campinas, Ed. da Unicamp, 1997c.

ZOPPI-FONTANA, Mónica. Cidade e discurso: paradoxos do real, do imaginário, do virtual. RUA-Revista do Núcleo de Desenvolvimento da Criatividade, n. 4, p.39-54., 1998.

ZOPPI-FONTANA, Mónica. Ordem jurídica, ordem política e a (des)ordem nas ruas. Discurso y Sociedad, v.1, n. 1., p. 105-122, 1999a. 
ZOPPI-FONTANA, Mónica. É o nome que faz fronteira. In: INDURSKY, Freda. (ed.) O Múltiplo território da Análise do Discurso. Porto Alegre, Sagra-Luzzatto, 1999b, p. 202-215.

ZOPPI-FONTANA, Mónica. Leitura, silêncio, memória. Leituras urbanas e práticas de exclusão. In: LEFFA, J. \& A. ERNST PEREIRA $O$ ensino da leitura e produção textual: alternativas de renovação. Pelotas, EDUCAT, 1999b, p.51-68.

ZOPPI-FONTANA, Mónica. Um estranho no ninho: entre o jurídico e o político, o espaço público urbano. Em: RUA-Revista do Núcleo de Desenvolvimento da Criatividade, número especial. Campinas, NUDECRI, 1999d, p. 53-65.

ZOPPI-FONTANA, Mónica. Lugares de enunciação e discurso. In: Leitura-Análise do Discurso. Revista do Programa de Pós-graduação em Letras e Lingüística. n. 23, p. 15-24, jan/jun 1999, 2002. ZOPPI-FONTANA, Mónica. Identidades (in)formais. Contradição, processos de designação e subjetivação na diferença. ORGANON, v.17, n.35, p.45-282, jan/dez 2003. 